\title{
The Need for the Inclusion of Multi-Criteria Decision Analysis in Architectural Design Education in Nigeria
}

\author{
Ebhomien L. E. ${ }^{1, *}$, Obarisiagbon O. ${ }^{1}$, Omorogbe, H. ${ }^{1}$ and Omobude, I.F. ${ }^{1}$ \\ ${ }^{1}$ Department of Architecture, University of Benin, Benin City, Nigeria \\ Corresponding Author:*ehimen.ebhomien@uniben.edu
}

\begin{abstract}
The inclusion of multi-criteria decision making (MCDM) methodologies as functional design tools in architecture has become a staple feature in architectural studies and research work. The trend while necessitated by challenges presented by the actualities involved in architectural practice, takes for granted the acceptability and knowledgeability of the built environment professional. This study highlights the fact that for MCDM to find general adoption and to provide its benefit in widespread solutions, the architect to whom these methodologies are advanced, should have an introduction to these approaches, formally at the educational level. Therefore, this paper evaluates the need for the inclusion of MCDM in architectural curriculum in Nigerian schools of architecture. The views of practicing professional architects, faculty members and students, were quantitatively and qualitatively analysed in a cross-sectional survey administered via questionnaires. A total of 54 respondents were evaluated, with findings of the study, indicating the novelty of MCDM and a general consensus for its introduction into the architectural curriculum, but varied opinions at what stage it should be introduced: 64\% (undergraduate level); 26\% (Masters' level) and 10\% (postmasters' level). Consequently, the study recommended that MCDM be introduced at the undergraduate level, because students would be better situated intellectually to apply, modify and diversify the methodology in architectural problem modelling in the long run.
\end{abstract}

Keywords: Multi-Criteria Decision Making, Architectural curriculum, Architecture Schools, Nigeria.

\subsection{Introduction}

Architectural education is seminal to the adaptability of today's architect to the current issues that redefine the design process. Several studies have emphasised the need to upgrade the training of Nigerian architectural educators and students on how to apply design management techniques to provide architectural solutions to challenges such as climate change, environmental conservation, social disintegration, poverty, natural resource depletion, and financial instability (Adegbile, 2012).

Over the last several decades, Multi-Criteria Decision Analysis (MCDA) has been used as a method to achieve incredible amount of decisions across various of fields, such as medicine, healthcare, environmental planning, forestry, economics and finance, energy management, transportation, public services, marketing, human resources management, construction industry and many other fields to support the resolution of decision problems of different nature and complexity (Sapienza et al., 2016).

According to Harputlugil et al. (2011), architectural design is considered to be a decision making process, within the process, decisions are taken by the evaluation of criteria and sub-criteria from the perspectives of stakeholders, allied professionals and clients related to various limitations suggesting that a veritable tool for architectural design management may be a multi-criteria methodology because multi-criteria decision making methods deal with the process of making decisions in the presence of multiple criteria.

These multi-criteria decision making methods considers several activities which in the context of current issues will include climate change, sustainability, green-house emissions, global warming and 
energy crisis and other increasingly complex activities, resulting in more design and performance evaluation variables in assessing design quality.

MCDM can be defined as the evaluation of different design alternatives and solutions for the purpose of selecting or ranking, based on qualitative and/or quantitative criteria that have different preferential values or weights. Architectural design is basically a stagewise non-standardized process involving many parameters and multifaceted interactions and feedback among several stakeholders like clients, allied professionals and project managers etc, each of which has impact on the decision in arriving at a design solution (Harputlugil et al.,2011).

Therefore, for the Nigerian architect to be equipped as a global player in an increasingly challenging environment, he/she must be trained in specialized tools such as MCDM, which can help simplify the decision-making process.

Balcomb and Curtner, (2000), applied MCDM on a process designed to facilitate two key decision points early in the design process critical to a building's sustainability. They discovered processes and tools that will assist the design team in prioritizing their goals, setting performance targets, and evaluating design options to ensure that the most important issues affecting building sustainability are considered.

Kristo et al., (2012) used six methods in the comparative study of MCDM for building design; the weighted sum method, the weighted product method, VIKOR, TOPSIS, PROMETHEE II, and a procedure based on the PEG-theorem, their results indicated that in most cases, the methods provided different solutions. The PEG-procedure tended to find a well-balanced solution.

Andresen (2000) applied Multi-Criteria Decision-Making Method for Solar Building Design based on the assumption that the success of solar buildings relies on the assessment and integration of all the different design criteria. He found that many of the existing MCDM models are very complicated and difficult to understand and use.

Harputlugil et al., (2011), highlighted the strength and weaknesses of current assessment tools and problem in the methodology used to implement MCDM methods for design quality assessment and proposed that future architecture assessment tools should be flexible and adaptable to building types, processes and project team; adaptable to stakeholders preferences and must put out not only assessment scores but also provide methodologies about transferring the data to be used as knowledge within the design process.

Elango et al, (2014), in an architectural studio project in which students were given a design brief to create alternative design solutions by morphological variations, made amendment to studio practice and curriculum, by demonstrating the importance of the multi-criteria approach over intuitive design approach in architecture. They discovered that intuitive judgement and single objective decision alone cannot be used to judge the alternative to predict the best possible design with the possible minimum information by any designer which can be accessible during the pre-design stage.

Given that the literatures above have shown that there are processes, tools and methods through which MCDM can be implemented in architectural design and training, this paper sought to evaluate the perceptions of professional architects, students and faculty members towards the application of multicriteria decision analysis in the architectural design process and also assessed the need for the implementation of MCDM in the design process and its inclusion in the Nigerian architectural curriculum.

It is the thrust of this study, that the trainee architect be introduced early enough to these methodologies so as to have a good head start and competitive advantage in architectural design and construction domains. In acknowledging the fact that any progress in this direction must be sanctioned and first acceptable to stakeholders in the built environment, this study undertakes a sampling of opinions of architecture professionals and academics; and also students who are grappling with traditional architectural problems in the face of an evolving environment. 


\subsection{Materials and Methods}

\subsection{Study Area}

The study area was Benin City and the Faculty of Environmental Science at the University of Benin. Benin City is the capital of Edo State in southern Nigeria. It is located between Latitudes $6^{\circ} 17^{\circ}$ and $6^{\circ}$ $26^{\circ}$ north and longitudes $5^{\circ} 351$ and $5^{\circ} 411$ East. Benin City is a unique city, by reason of the fact that it is an intersecting city that connects Northern, Southern and Western parts of the country via its road network.

The City was chosen for the survey because of the diverse educational background of its practising architects who were all trained outside the city because three years before now this city had no architecture school. Also Benin City boasts of a demographic distribution of the population which cuts across different educational and socio-economic strata. The faculty of environmental science at the university of Benin is made up of 4 departments; Architecture, Estate management, Geomatics and Quantity Surveying.

\subsection{Method of Data Collection}

Questionnaires were administered to practicing architects in the city, faculty members and students of the faculty of environmental science in the University of Benin, through purposive sampling. Purposive sampling was conducted given the nature of the research which was to evaluate the perception of Architects, faculty members and students who had some level of experience in architectural practice and academics.

The research questionnaires evaluated the perceptions of professional architects, students and faculty members towards the application of multi-criteria decision analysis in the architectural design process. This was done to evaluate the need for the implementation of MCDM in the design process and its inclusion in the Nigerian architectural curriculum. A sample size of 21 Architects, 23 faculty members and 10 students was used for the study which lasted for a period of six weeks.

\subsection{Results and Discussion}

At the end of the survey, 54 questionnaires of the total of 70 administered were returned. This corresponded to a response rate of $77 \%$. The deficit of $23 \%$ was recorded because some respondents did not return their questionnaires. The data derived from the questionnaire were analysed using frequency counts and percentages and the results are presented in Figures 1 and 2.

Figure 1 shows the distribution of the respondents. 39\% were practising architects in Benin City, 43\% were faculty members at the Faculty of Environmental Science in the University of Benin and $18 \%$ were students of the Department of Architecture in the same university.

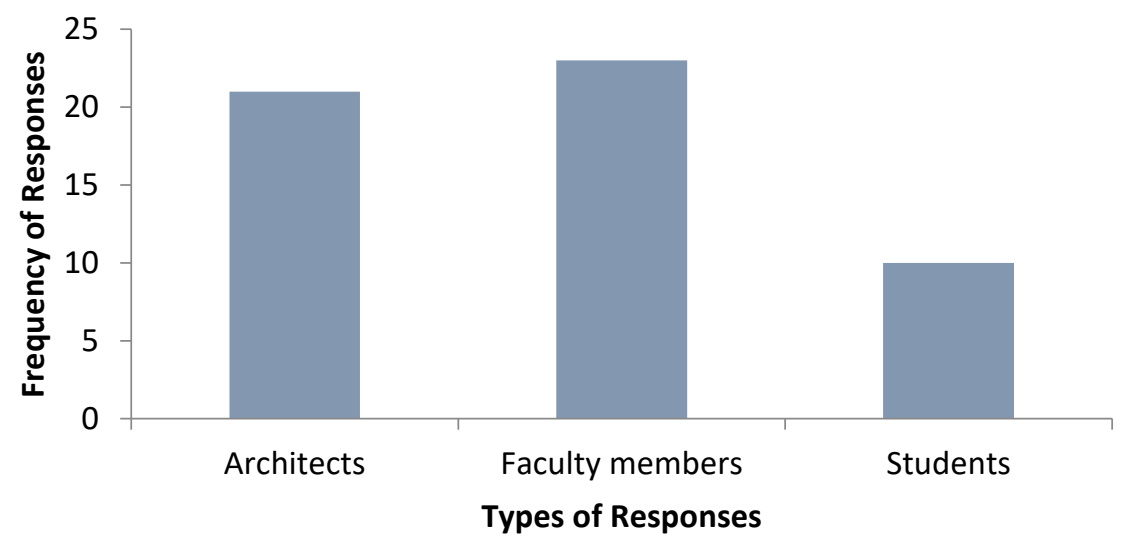

Figure 1: Distribution of respondents

Figure 2 shows the responses on awareness and perception of MCDM. 92\% of the respondents had no prior knowledge of MCDM while 8\% were not grounded in the knowledge. This shows a low level of 
awareness and knowledge on the MCDM methodology indicating a knowledge gap in use, teaching and deployment of this method. $98 \%$ of the respondents agreed that MCDM will be beneficial to architecture even though a large majority of them had no knowledge about it which highlights the problem of the study; the need for implementation of MCDM in the design process and its inclusion in the Nigerian architectural curriculum.

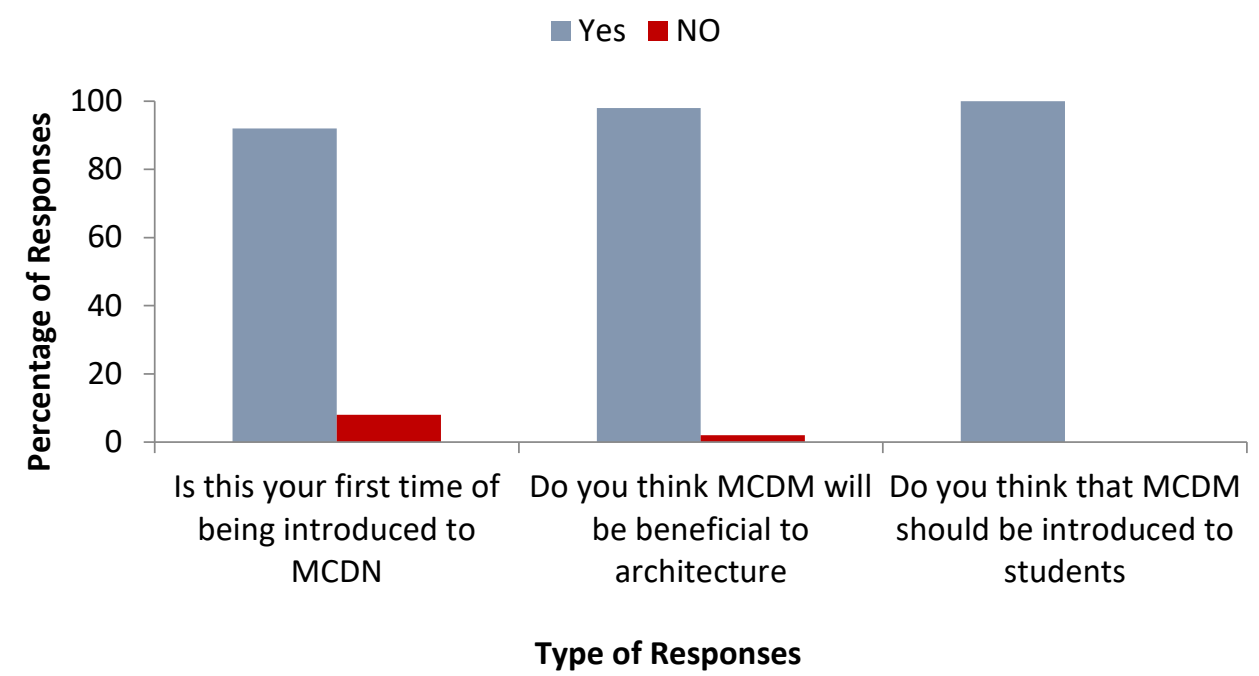

Figure 2: Summary of responses on the awareness and perception of MCDM.

Figure 3 shows a summary of response to the question "At what level should MCDM be introduced to students?" All the respondents agreed that MCDM should be introduced to students but had varied opinions at what stage it should be introduced. $64 \%$ of the respondents agreed that MCDM should be introduced at the undergraduate level, $26 \%$ were in support of it been introduced to the architectural curriculum at the masters level, while only $10 \%$ supported the introduction of MCDM to architecture students at the post-masters level.

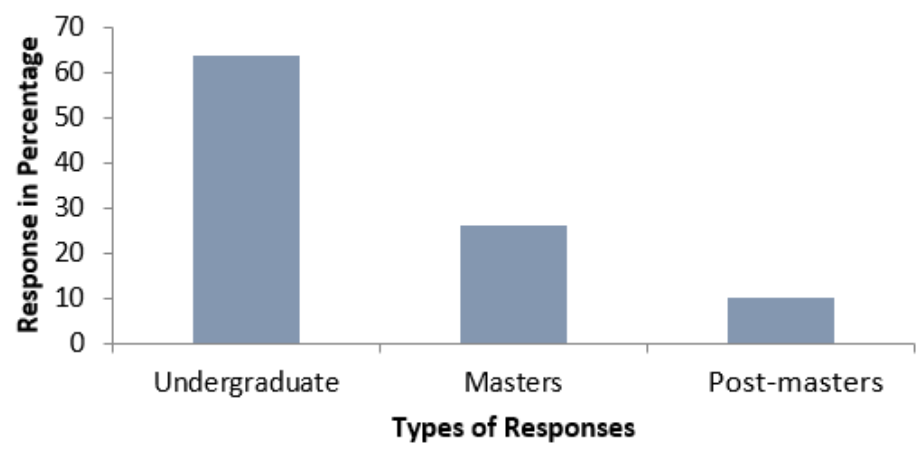

Figure 3: Summary of the responses on the stage MCDM should be introduced to architecture curriculum.

\subsection{Response to Interview-Type Questions}

For the question "How were you introduced to MCDM?" All the respondents who had some prior knowledge of MCDM (8\%), were introduced or encountered MCDM through studies and papers, applying the approach. For the question "How many MCDM methods do you know?" The responses revealed that the respondents despite a previous knowledge through literature study of MCDM were not knowledgeable about the methodology, as many of them could not specify any MCDM method, and the very few who did gave wrong answers. 


\subsection{Conclusion}

The study showed that the majority of the respondents had a low level of awareness and knowledge on the MCDM methodology and that the few who had an idea of MCDM were not well-grounded in their knowledge. After a brief introduction to the concept of MCDM, the respondents were of the general consensus that MCDM would be a most veritable tool in enhancing design quality and resolving the complex issues of decision making in architectural design. The study revealed a case of respondents discovering a new tool they never knew existed that could solve exigent and practical problems in their area of practice.

Consequently, this study recommends that MCDM be introduced at the undergraduate level, as its benefits and applications are wide ranging and useful in studio practice, and also because when students are introduced early enough, and they train to apply the methodology in simple cases, they would be better situated intellectually to apply, modify and diversify the methodology in architectural problem modelling, in the long run.

Also, it is recommended that other studies should be conducted by indigenous architects testing and applying the methodology in solving local problems, as this would demonstrate MCDM performance and improve its acceptability.

\section{Acknowledgement}

The authors are thankful to our colleagues at the Faculty of Environmental Science in the University of Benin, Benin City, Nigeria who provided expertise that greatly assisted this work although they may not agree with all the interpretation provided in this paper. We are also grateful to every questionnaire respondent for their time.

\section{References}

Adegbile, M. (2012). Nigerian architectural education in a sustainable age. Presented at Sustainable Futures: Architecture and Urbanism in the Global South, Kampala, Uganda, 27-30 June, 2012.

Andresen, I. (2000). A multi-criteria decision-making method for solar building design. (Doctoral dissertation), Retrieved from the Norwegian University of Science and Technology, Faculty of Architecture, Planning and Fine Arts, Department of Building Technology, Norway.

Balcomb, J. D. and Curtner . A. (2000). Multi-criteria decision-making process for buildings. Presented at the American Institute of Aeronautics and Astronautics Conference, Las Vegas, Nevada July 24-28, 2000 .

Elango, M. and Devadas, M. D. (2004). Multi-Criteria Analysis of the Design Decisions In Architectural Design Process during the Pre-Design Stage. International Journal of Engineering and Technology (IJET), 6 (2), 1033-1046.

Kristo, M., Teemu, T., Markku, H., (2012). Comparative study of multiple criteria decision making methods for building design. Advance engineering informatics archive, 26 (4), 716-726.

Harputlugil, T., Prins, M., Tanju G. A., Ilker T. Y. (2011). Conceptual framework for potential implementations of multi criteria decision making (MCDM) methods for design quality assessment. Presented at Management and Innovation for a Sustainable Built Environment, 20 - 23 June 2011, Amsterdam, The Netherlands.

Sapienza, G., Brestovac, G., Grgurina, R., Seceleanu, T. (2016). On applying multiple criteria decision analysis in embedded systems design. Design Automation for Embedded Systems, 20, (3), 211-238. 